\title{
Oxime Reactivators and Their in Vivo and in Vitro Effects on Nicotinic Receptors
}

\author{
O. SOUKUP ${ }^{1,6}$, J. KRŮŠEK ${ }^{4}$, M. KANIAKOVÁ ${ }^{4}$, U. K. KUMAR ${ }^{3}$, M. OZ $^{5}$, D. JUN $\mathbf{N}^{1,2}$, \\ J. FUSEK ${ }^{1}$, K. KUČA ${ }^{1,2}$, G. TOBIN ${ }^{3}$ \\ ${ }^{1}$ Department of Toxicology, Faculty of Military Health Sciences, University of Defence, Hradec \\ Králové, Czech Republic, ${ }^{2}$ Center of Advanced Studies, Faculty of Military Health Sciences, \\ University of Defence, Hradec Králové, Czech Republic, ${ }^{3}$ Institute of Neuroscience and \\ Physiology, Department of Pharmacology, the Sahlgrenska Academy at University of Gothenburg, \\ Sweden, ${ }^{4}$ Institute of Physiology, Academy of Sciences of the Czech Republic, Prague, Czech \\ Republic, ${ }^{5}$ Department of Pharmacology and Therapeutics, Faculty of Medicine, United Arab \\ Emirates University, Al Ain, United Arab Emirates, ${ }^{6}$ University Hospital Hradec Králové, Czech \\ Republic
}

Received October 22, 2010

Accepted February 21, 2011

On-line May 16, 2011

\begin{abstract}
Summary
Current treatment of organophosphorus poisoning, resulting in overstimulation and desensitization of muscarinic and nicotinic receptors by acetylcholine ( $\mathrm{ACh})$, consists of the administration of atropine and oxime reactivators. However, no versatile oxime reactivator has been developed yet and some mortality still remains after application of standard atropine treatment, probably due to its lack of antinicotinic action. In our study, we focused on the interesting non-acetylcholinesterase property of oximes, i.e. antinicotinic effect of reactivators. Two standard reactivators (HI-6, obidoxime) and two new compounds (K027 and $\mathrm{K} 203$ ) were chosen for in vitro (patch clamp) and in vivo (nerve-evoked muscle contraction) testings. Both examinations showed antinicotinic effects of the reactivators. In vitro inhibition of acetylcholine-evoked currents by obidoxime, HI- 6 and K203 was equivalent while K027 was less potent. Similar order of potency was observed by the in vivo examinations. We thus confirm previous in vitro results, which describe antinicotinic effects of oxime reactivators, and furthermore, we show in vivo antagonism of oxime reactivators exerted by the inhibition of ACh effect on the nicotinic receptor in the neuromuscular junction. Taking together, the effects of tested oxime reactivators indicate an antagonism on both embryonic and adult form of the muscle nicotinic receptors.
\end{abstract}

\section{Key words}

Organophosphates - Patch-clamp - Nicotinic receptors • Reactivator • Isometric muscle contraction • TE671 cells

\section{Corresponding author}

O. Soukup, Department of Toxicology, Faculty of Military Health Sciences, University of Defence, Třebešská 1575, 50001, Hradec Králové, Czech Republic. Fax: +420 495518094 . E-mail: soukup.ondrej@seznam.cz

\section{Introduction}

Organophosphates (OP) are compounds, which inhibit the enzyme acetylcholinesterase (AChE, EC 3.1.1.7) via phosphorylation or phosphonylation of serine hydroxyl group at its active site (Radic and Taylor 2006). AChE inhibitors, according to their potency, can be grouped into either nerve agents (such as sarin, soman, tabun and VX) or pesticides (such as paraoxon, parathion and chlorpyrifos) (Marrs 1993). AChE inhibition results in accumulation of acetylcholine (ACh) at cholinergic receptor sites, leading to the overstimulation of cholinergic receptors in both the central and the peripheral nervous system (Bajgar 2004).

The treatment is ensured by two functionally different types of drugs: (1) Reactivators of AChE - 
oximes - are able to restore the physiological function of inhibited AChE and (2) Anticholinergics, such as atropine, are able to antagonize the effects of excessive ACh by a blockade of muscarinic receptors. Anticholinergics and reactivators may be administered together because of their synergistic effect (Kassa 2002, Bajgar 2004).

Current treatment of organophosphorus poisoning consists of the administration of atropine and oxime reactivator (mostly HI-6 or obidoxime), and, for anticonvulsant effects, diazepam may occasionally be employed. Atropine has been used for 50 years in clinical practice to control the overstimulation caused by AChE inhibitors (Sivagnanam 2002). However, $20 \%$ mortality still remains after application of standard atropine treatment (Eddleston et al. 2008). An explanation to this persisting mortality could be the lack of in vivo nicotinic antagonism of the compound (Tobin et al. 1991, Luo et al. 2010).

HI-6 and obidoxime are the most commonly used oxime reactivators in the treatment of organophosphorus poisoning. HI-6, a broad-spectrum antidote, is considered to be the most effective and is effective against soman, sarin and VX (Kassa 2002), but it is less effective against tabun (Puu et al. 1986). On the other hand, obidoxime is used in the treatment of both poisoning by tabun as well as by pesticides (Kassa 2002).

Despite of all this knowledge, the treatment of organophosphorus poisoning is still limited due to the following reasons: 1 . No versatile antidote capable to effectively restore activity of AChE inhibited by random organophosphates has been developed. 2. Oxime reactivators are efficient only when administered before the "aging" of AChE-OP complex. 3. Anticholinergics, like atropine, are effective only on muscarinic and not on nicotinic receptors (nAChRs). Owing to this fact, new $\mathrm{AChE}$ reactivators, capable of reactivating $\mathrm{AChE}$ irrespective of the type of nerve agent used are thus required. Alternatively, other treatment approaches need to be introduced.

Such an alternative approach presumes other mechanisms of oximes, not related to the reactivation (Hamilton and Lundy 1989, van Helden et al. 1992, 1996, Tattersall 1993, Soukup et al. 2010a). Oximes have been reported to act at several levels of the cholinergic transmission including synthesis, release, inactivation and re-uptake of the transmitter, but the interaction with cholinoreceptors has been put forward as the most plausible alternative of mechanism of action (Tattersall
1993, van Helden et al. 1996). Both standard reactivators, obidoxime (Soukup et al. 2010b) and HI-6, (Hamilton and Lundy 1989, Soukup et al. 2008) have been reported to exert some antimuscarinic properties. Antinicotinic action, which atropine lacks and which can prevent respiratory failure, has also been reported. Both neuromuscular blocking (Schlagmann et al. 1990, Tattersall 1993, Chiou and Chang 1994) and ganglioblocking (Lundy and Tremblay 1979, Schlagmann et al. 1990) types of antinicotinic action have been reported. However, the reported in vitro properties do not correlate with the antidotal observations in vivo.

In our study, we have chosen two standard reactivators (HI-6, obidoxime) and two newly synthesized promising compounds (K027 and K203) in order to investigate their antinicotinic properties (for structure see Fig. 1). K027 may become the preferred antidote in the treatment of poisoning by pesticides (Petroianu et al. 2007) and K203 is an effective compound in cases of inhibited AChE by tabun (Kovarik et al. 2009). We examined the differences in antinicotinic efficacy of the individual reactivators in vitro, and further, we wondered if the in vitro findings had any in vivo significance.

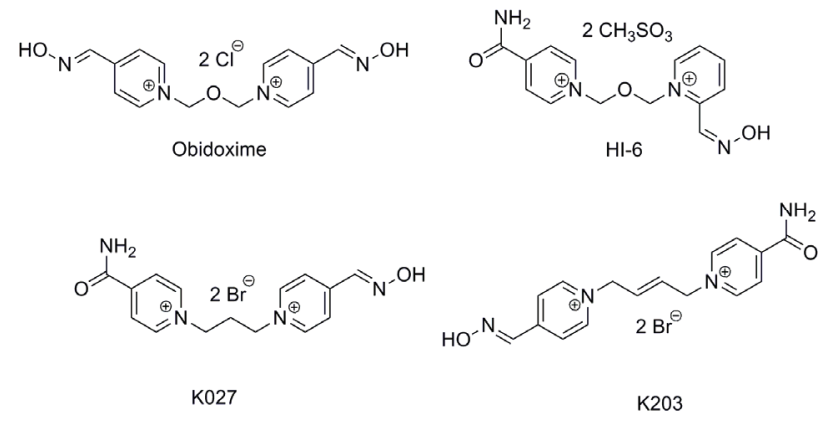

Fig. 1. Structures of tested oximes.

\section{Materials and Methods}

In vivo measurement of neuromuscular block

The animal ethics committee at the University of Gothenburg approved the experiments of the present study.

Male rats of the Sprague-Dawley strain (200$300 \mathrm{~g})$ were anaesthetized with pentobarbitone (45 mg/kg, IP) and ketamine (50 mg/kg, IM) followed by supplementary doses injected intravenously as required during the experiments. Nerve-evoked maximal twitches of the tibialis anterior muscle of the right lower limb of 
the rat was monitored as described previously (Tran et al. 1982). The free tendon of the tibialis anterior muscle was attached to a force transducer (Biopac, Goleta, USA) by a thread, while the right lower limb was kept immobilized. The resting tension of the muscle was adjusted to approximately $20-30 \mathrm{mN}$. A $3 \mathrm{~cm}$ incision was made from the gluteal region to the middle of the thigh. The muscle was carefully dissected to expose $2.0-2.5 \mathrm{~cm}$ of the sciatic nerve. The sciatic nerve was stimulated $(1 \mathrm{~Hz}$ or $5 \mathrm{~Hz}$ for $10 \mathrm{~s}$ every $60 \mathrm{~s}, 4 \mathrm{~V}, 0.8 \mathrm{~ms}$ ) with an electrode connected to a stimulator (Grass stimulator S88, Grass technologies, USA) to produce maximal twitches of the tibialis anterior muscle. Twitches were recorded in the presence and in the absence of a oxime reactivator. Reactivators were administered in a cumulative manner, I. V. (femoral vein) in four doses $(10 \mu \mathrm{g}, 100 \mu \mathrm{g}, 1 \mathrm{mg}$ and $10 \mathrm{mg}$ per $\mathrm{kg}$ ) and the stimulation (recording) was performed after $60 \mathrm{~s}$ from administration by stimulation frequencies at $1 \mathrm{~Hz}$ and $5 \mathrm{~Hz}$ applied for $10 \mathrm{~s}$. The recording was done in duplicate, $60 \mathrm{~s}$ after the previous recording. The isometric twitches or tetanic tensions were continuously recorded. Data were recorded by MP100WSW data acquisition system and ACQKnowledge software (Biopac, Goleta, USA).

In vitro measurement of direct nicotinic receptor inhibition by the patch-clamp technique

The direct inhibitory effects of compounds were measured as the diminution of cationic current responses induced by $10 \mu \mathrm{M}$ acetylcholine on the nicotinic receptors. The ability of reactivators to inhibit ACh responses was then quantified.

The experiments were performed on TE671 cell line, which is medulloblastoma cell line endogenously expressing human embryonic muscle-like acetylcholine receptor (Schoepfer et al. 1988). Even though the cell line is of neuronal origin, rhabdomyosarcoma properties has been described too (Stratton et al. 1989). The whole-cell mode of patch-clamp method using an Axopatch 200A amplifier (Axon Instruments, Foster City, CA, USA) was applied. TE671 cells (kindly provided by Dr. Jan Ricny) were cultivated at $37{ }^{\circ} \mathrm{C}$ under $5 \% \mathrm{CO}_{2}$ atmosphere in a minimal essential medium (D-MEM), which was supplemented with $10 \%$ of fetal calf serum (Dr. Kysilka, Brno). Nicotine $(100 \mu \mathrm{M})$ was added to cultivation medium 2-3 days before measurement to increase nAChRs expression (Ke et al. 1998).

Fire-polished glass micropipettes with an outer diameter of approx. $3 \mu \mathrm{m}$ were filled with a solution of the following composition (in $\mathrm{mM}$ ): $\mathrm{CsF} 110, \mathrm{CsCl} 30$, $\mathrm{MgCl}_{2}$ 7, $\mathrm{Na}_{2}$ ATP 5, EGTA 2, HEPES-CsOH 10, pH 7.4. The resistances of the microelectrodes were 3 to $5 \mathrm{M} \Omega$. The cell bath solution contained (in $\mathrm{mM}$ ): $\mathrm{NaCl} 160, \mathrm{KCl}$ 2.5, $\mathrm{CaCl}_{2} 1, \mathrm{MgCl}_{2} 2$, HEPES-NaOH 10, glucose 10, $\mathrm{pH}$ 7.3. Solutions of drugs were applied using a rapid microperfusion system (Mayer et al. 1989) consisting of an array of 12 parallel quartz-glass tubes each approximately $400 \mu \mathrm{m}$ in diameter. The tubes were positioned and the flow of different solutions was switched on/off under microcomputer control (Mayer et al. 1989, Vyklicky et al. 1990). A complete change of the solution around the cell could be carried out in 20 to $60 \mathrm{~ms}$. For signal recording and evaluation of data, an Axon Instruments Digidata 1440A digitizer and pCLAMP10 software package (Axon Instruments, Foster City, CA) were used. Data were low-pass filtered at $1 \mathrm{kHz}$ and digitized at $2 \mathrm{kHz}$. Cells were held at $-40 \mathrm{mV}$ during recordings.

Ionic current was induced by application of $10 \mu \mathrm{M}$ ACh for $5 \mathrm{~s}$. The solution of inhibitor was applied as $10 \mathrm{~s}$ preapplication followed by the application together with $10 \mu \mathrm{M}$ ACh.

\section{Data analysis}

All data values are expressed as mean \pm S.E.M. Statistical significance of in vivo experiment was determined by one-way analysis of variance (ANOVA) followed by the Dunnet's multiple-comparison test. All statistical analyses were performed on raw data, but the graphs are presented in percentage. P-values less than 0.05 were regarded as statistically significant. Graphs were generated by using the GraphPad Prism software (GraphPad Software, Inc., San Diego, USA).

As current responses of TE671 cells vary with time, regular periodic applications of 10 micromolar ACh were used as a control of cell sensitivity in the patch clamp technique. Corrected relative value of inhibition was calculated by dividing the amplitude of inhibited response by the average of two surrounding control responses.

\section{Chemicals}

HI-6, (1-(2-hydroxyamino-methylpyridinium)-3(4-carbamoylpyridinium)-2-oxapropane dimethansulfonate); obidoxime, (1,3-bis(4-hydroxyiminomethylpyridinium)-2-oxapropane dichloride); K027, (1-(4hydroxyiminomethyl pyridinium)-3-(4-carbamoylpyridinium) propanedibromide); and K203 ([(E)-1-(4-carba- 
A

HI-6

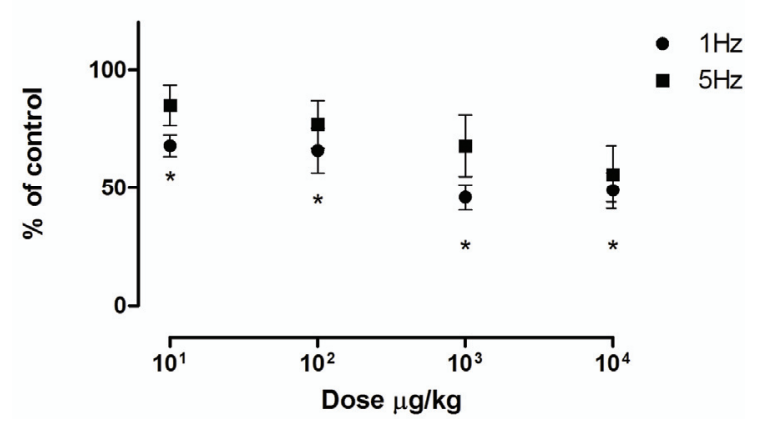

C

\section{K027}

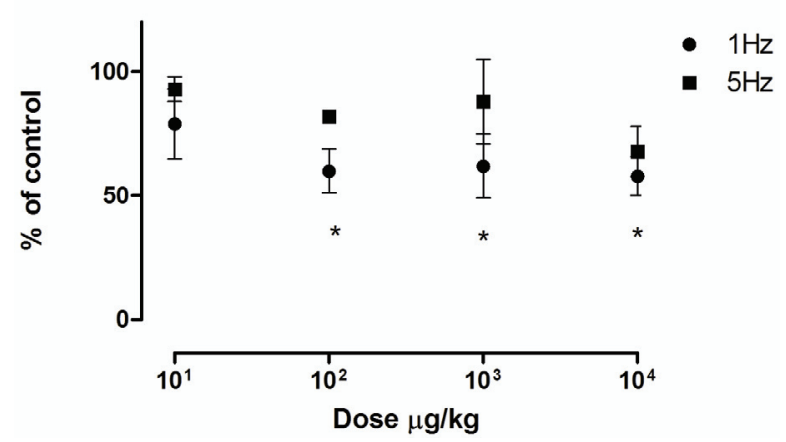

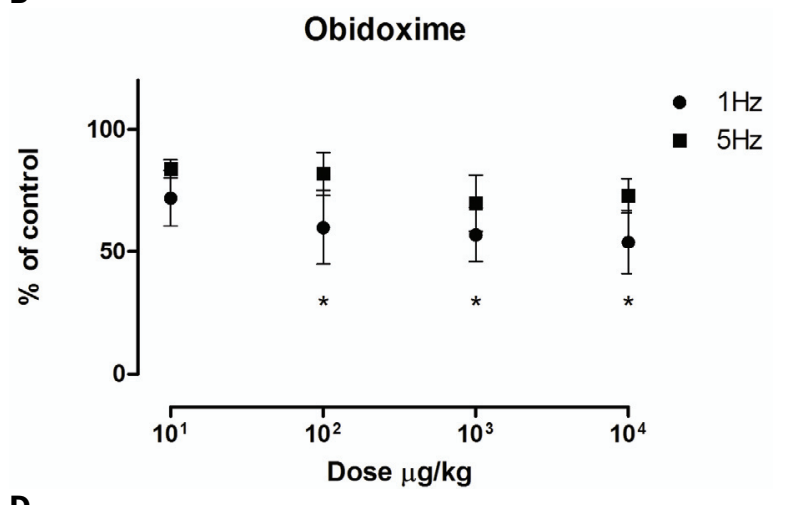

D

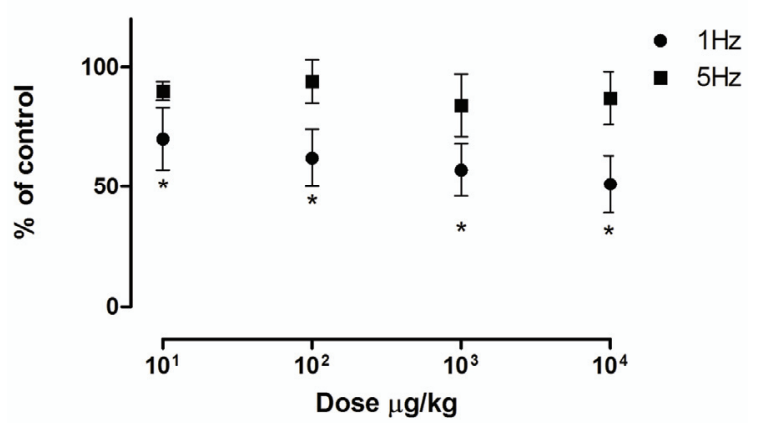

Fig. 2. The effect of various reactivators on the amplitude of the muscular twitches produced by electrical stimulation $(1 \mathrm{~Hz}$ or $5 \mathrm{~Hz})$. Data are shown in percentage. All values are expressed as mean \pm S.E.M. $*$ indicates the statistically significant difference $(p<0.05)$ from the basal response (absence of tested compound).

moylpyridinium)-4-(4-hydroxyiminomethylpyridinium)but-2-ene dibromide) were synthesized at the Department of Toxicology, Faculty of Military Health Sciences, University of Defence, Hradec Králové, Czech Republic. Pentobarbitone, Ketalar (Apoteket AB, Sweden) were obtained from the commercial sources.

Acetylcholine chloride was from Merck (Darmstadt, Germany), tissue culture media D-MEM was from GIBCO (Invitrogen, Carlsbad, California, USA) and all other chemicals were from Sigma Aldrich (St. Louis, MO, USA)

\section{Results}

In vivo measurement of neuromuscular block

The basal amplitude of muscle twitches was $512 \pm 25 \mathrm{mN}(\mathrm{n}=20)$ at $1 \mathrm{~Hz}$ and $902 \pm 88 \mathrm{mN}(\mathrm{n}=19)$ at $5 \mathrm{~Hz}$ stimulation; an illustrative typical muscle twitches recording is shown (Fig. 3). The lowest dose of reactivators $(10 \mu \mathrm{g} / \mathrm{kg} \quad$ I.V.) caused reductions by $28 \pm 5 \%, 32 \pm 4 \%, 21 \pm 6 \%, 30 \pm 6 \%$ at $1 \mathrm{~Hz}(\mathrm{n}=5, \mathrm{p}<0.05)$ and only $16 \pm 2 \%, 15 \pm 8 \%, 7 \pm 2 \%, 10 \pm 2 \%$ at $5 \mathrm{~Hz}$ in obidoxime groups, HI-6, K027 and K203, respectively $(\mathrm{n}=5)$. The largest dose administered (10 mg/kg I.V.) caused at $1 \mathrm{~Hz}$ even larger reductions, namely $46 \pm 6 \%$, $51 \pm 8 \%, 42 \pm 4 \%, 49 \pm 5 \%(\mathrm{n}=5, \mathrm{p}<0.05)$ for the same groups. On the other hand, at $5 \mathrm{~Hz}$, no such clear progress occurred $(37 \pm 3 \%, 46 \pm 12 \%, 32 \pm 5 \%, 13 \pm 5 \%)$ in the same groups $(n=5)$. The inhibition, if any, was less; statistical significance was attained only at $1 \mathrm{~Hz}$ (Fig. 2).

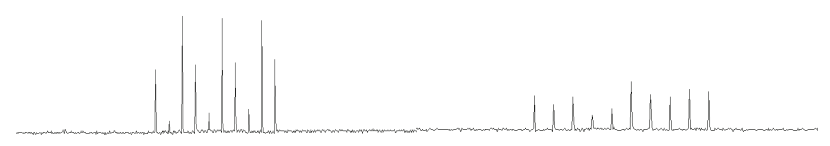

Fig. 3. Illustration of twitches recordings. Basal response at $1 \mathrm{~Hz}$ (left) and response at $1 \mathrm{~Hz}$ after administration of $\mathrm{HI}-610 \mathrm{mg} / \mathrm{kg}$ (right).

In vitro measurement of direct nicotinic receptor inhibition by the patch-clamp technique

The application of $10 \mu \mathrm{M}$ of acetylcholine to TE671 cells, clamped at $-40 \mathrm{mV}$ membrane potential, produced inward currents in the range of 200pA-7 nA. Superfusion of TE671 cells with ECS containing reactivator did not evoke any inward current (not shown). 
When reactivators were pre-applied and then co-applied together with ACh $10 \mu \mathrm{M}$, they reversibly inhibited ACh responses in a concentration-dependent manner. The inhibitory effect of tested drugs at the concentration of $200 \mu \mathrm{M}$ has been illustrated (Fig. 4). The comparison of reactivators' inhibitory activity at the concentration of $200 \mu \mathrm{M}$ is summarized in Table 1 .

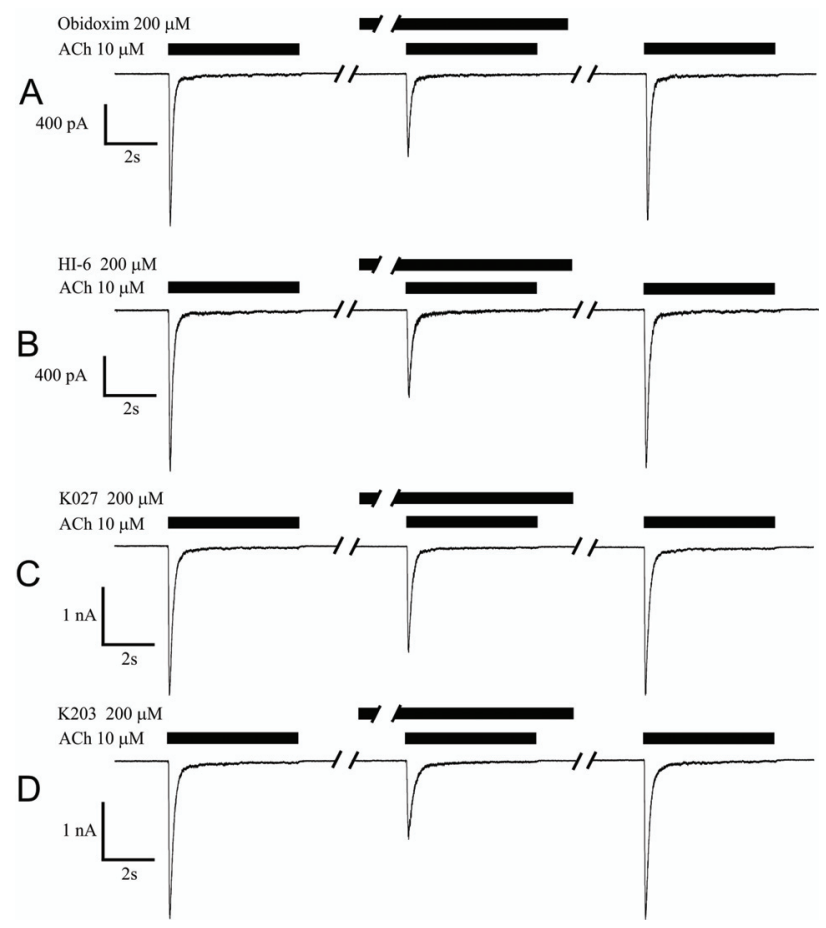

Fig. 4. Inhibition of human embryonic muscle receptors by oxime reactivators. Whole-cell membrane currents evoked by acetylcholine were recorded in the absence and in the presence of different oxime reactivators. Drugs, at $200 \mu \mathrm{M}$, were preapplied for $10 \mathrm{~s}$ and then coapplied with $10 \mu \mathrm{M} \mathrm{ACh}$ for $5 \mathrm{~s}$ as is indicated by bars. TE671 cells were clamped at $-40 \mathrm{mV}$. A) Obidoxime $200 \mu \mathrm{M}$, B) HI-6 $200 \mu \mathrm{M}$, C) K027 $200 \mu \mathrm{M}$, D) K203 $200 \mu \mathrm{M}$.

Table 1. Inhibition shows the drop (in percentage) in response caused by an individual reactivator at the concentration of $200 \mu \mathrm{M}$ on the ACh $10 \mu \mathrm{M}$ - evoked response (patch-clamp) ( $0 \%=$ no effect, $100 \%=$ complete inhibition). $\mathrm{N}$ stands for the number of cells used. S.E.M stands for the standard error of the mean.

\begin{tabular}{lccc}
\hline Reactivator & $\begin{array}{c}\text { Inhibition } \\
(200 \mu \mathrm{M})(\%)\end{array}$ & $\begin{array}{c}\text { S.E.M } \\
(\mathbf{\%})\end{array}$ & $\mathbf{N}$ \\
\hline Obidoxime & 51 & 2 & 4 \\
HI-6 & 45 & 1 & 4 \\
K027 & 31 & 1 & 3 \\
K203 & 50 & 1 & 3 \\
\hline
\end{tabular}

\section{Discussion}

The principal mechanism of action of oxime antidotes is the reactivation of inhibited AChE. But still, the pharmacological effect of oximes is an open question. Doubtlessness, oximes affect the cholinergic transmission at several levels, and antimuscarinic and antinicotinic effects are two such sites (van Helden et al. 1996). Today, atropine is frequently used in order to reduce effects connected with excessive ACh stimulation during the OP poisoning. ACh is the transmitter both at the ganglionic level in the autonomic nervous system and at the skeletal neuromuscular junction, and a blockade caused by atropine in the therapeutical doses is not sufficient to hinder all ACh effects (Tobin et al. 1991, Luo et al. 2010). On the other hand, atropine-induced shortening of the endplate postsynaptic potentials has been reported in the frog neuromuscular junction (Beranek and Vyskocil 1967).

Previously, oximes have been shown to inhibit the nicotinic ion channel at the mouse muscle endplate and at the guinea-pig diaphragm preparations (Tattersall 1993). Furthermore, ganglioblocking properties has been suggested too (Lundy and Tremblay 1979, Kirsch and Weger 1981). However, contradictory observations exist and HI-6 and pralidoxime have been reported to also increase the opening probability of nicotinic receptors that are activated by ACh (Alkondon et al. 1988). It has also been shown that all cholinesterase inhibitors, in addition to their well-known anti-AChE activity, have multiple effects on the nicotinic ACh receptor-ion channel macromolecule. The effects on the nicotinic ACh receptor have been reported to be exerted by competitive antagonism and by different types of noncompetitive blockade (van Helden et al. 1996). In this context, it may be worth noting that binding and functional studies of the antagonism on muscarinic receptors have indicated a complexity in the mechanisms of action of oxime reactivators, which may be valid for the nicotinic antagonism as well (Amitai et al. 1980). Two elements for ligands are necessary to interact with $\mathrm{nAChR}$ in the orthosteric site: H-bond acceptor group and positively charged nitrogen (Romanelli and Gualtieri 2003). Both requirements are fulfilled by our oxime reactivators. However, only small changes in the chemical structure may shift activity from agonist to antagonist. On the other hand, allosteric modulators belong to structurally very heterogenous group. Furthermore, the dose employed may differentiate between opposite effects (Romanelli 
and Gualtieri 2003). From our observations, it is hard to deduce oximes' mechanism of inhibition; more mechanistically focused experiments should be performed.

In the present study, nicotinolytic effects were shown to occur in vivo when studied on a tibial muscle preparation. This confirms previous in vitro observations (Tattersall 1993). Taking experimental data together, oxime reactivators show an antagonism on both embryonic and adult form of the nicotinic receptors.

Furthermore, when the oxime effects were studied on the nicotinic channel in the TE671 cell line, inhibitory effects were also observed. In vivo, a difference between $1 \mathrm{~Hz}$ and $5 \mathrm{~Hz}$ stimulation was obvious. At $5 \mathrm{~Hz}$ stimulation, smaller inhibitory effects appeared, probably due to a larger availability of ACh at this frequency. Even though no statistical significance was shown, still dose-dependent effects seem to occur. It should be stressed that spontaneous fading of twitches may occur during a repetitive stimulation, probably due to changed sensitivity of the perceptual receptors (Van der Kloot et al. 1994). However, a decrease by $23 \%$ was reported after delivery of 3000 stimuli. In our study, only about 1000 stimuli were delivered and the reduction observed was up to $50 \%$. Concerning individual compounds only small differences in potency appeared. If any difference in potency occurred between the various oximes, it was somewhat less for K027. However, the same pattern occurred when examined in the TE671 cell line. The compounds examined are hydrophilic. Therefore, it may be assumed that they mainly distribute into the water compartment. Estimation of the $\mathrm{IC}_{50}$ values in the in vivo experiments based on such distribution volumes renders concentration ranges between 30 and
$150 \mu \mathrm{M}$, which roughly correspond to the estimative in vitro $\mathrm{IC}_{50}$ values (140-250 $\mu \mathrm{M}$ in case of obidoxime, HI-6 and $\mathrm{K} 203$; over $600 \mu \mathrm{M}$ in case of $\mathrm{K} 027$; data not shown). To the best of our knowledge, this is the first time that an oxime inhibition on nicotinic receptors is demonstrated in vivo.

However, since the nicotinic receptor activation was evoked by electrical nerve stimulation, effects on neuronal receptors may have influenced the results. As muscarinic receptors (M2) are present in the presynaptic part of neuromuscular synapse it is possible that this antimuscarinic action of the oxime reactivators could have played a role by the enhancing the release of neurotransmitters (Santafe et al. 2004)

In conclusion, we confirm previous results showing in vitro inhibitory effect of oximes on nicotinic receptors, and further, we show that the nicotinic neuromuscular antagonism of oxime reactivators occurs in vivo, as well. Obidoxime, HI-6 and K203 show similar potency, while $\mathrm{K} 027$ is less potent to inhibit ACh-evoked current mediated by stimulation of the nicotinic ACh receptor. Unselective nicotinic antagonism is indicated by the fact, that similar antinicotinic action was observed in two different sources of nicotinic receptors.

\section{Conflict of Interest}

There is no conflict of interest.

\section{Acknowledgements}

This work was supported by the grant of Ministry of Defense (Czech Republic) No. FVZ0000604, GAČR 202/09/0806, GAČR P303/11/1907, AV0Z 50110509 and LC554.

\section{References}

ALKONDON M, RAO KS, ALBUQUERQUE EX: Acetylcholinesterase reactivators modify the functional properties of the nicotinic acetylcholine receptor ion channel. J Pharmacol Exp Ther 245: 543-556, 1988.

AMITAI G, KLOOG Y, BALDERMAN D, SOKOLOVSKY M: Interaction of bis-pyridinium oximes with mousebrain muscarinic receptor. Biochem Pharmacol 29: 483-488, 1980.

BAJGAR J: Organophosphates/nerve agent poisoning: mechanism of action, diagnosis, prophylaxis, and treatment. $A d v$ Clin Chem 38: 151-216, 2004.

BERANEK R, VYSKOCIL F: The effect of atropine on the frog sartorius neuromuscular junction. J Physiol 195: 493$503,1968$.

EDDLESTON M, BUCKLEY NA, EYER P, DAWSON AH: Management of acute organophosphorus pesticide poisoning. Lancet 371: 597-607, 2008.

HAMILTON MG, LUNDY PM: HI-6 therapy of soman and tabun poisoning in primates and rodents. Arch Toxicol 63 : 144-149, 1989. 
CHIOU LC, CHANG CC: Obidoxime antagonizes the neuromuscular failure induced by neostigmine and diisopropyl fluorophosphate via different mechanisms. J Biomed Sci 1: 19-27, 1994.

KASSA J: Review of oximes in the antidotal treatment of poisoning by organophosphorus nerve agents. $J$ Toxicol Clin Toxicol 40: 803-816, 2002.

KE L, EISENHOUR CM, BENCHERIF M, LUKAS RJ: Effects of chronic nicotine treatment on expression of diverse nicotinic acetylcholine receptor subtypes. I. Dose- and time-dependent effects of nicotine treatment. J Pharmacol Exp Ther 286: 825-840, 1998.

KIRSCH DM, WEGER N: Effects of the bispyridinium compounds HGG12, HGG42, and obidoxime on synaptic transmission and $\mathrm{NAD}(\mathrm{P}) \mathrm{H}$-fluorescence in the superior cervical-ganglion of the rat in vitro. Arch Toxicol 47: 217-232, 1981.

KOVARIK Z, VRDOLJAK AL, BEREND S, KATALINIC M, KUCA K, MUSILEK K, RADIC B: Evaluation of oxime k203 as antidote in tabun poisoning. Arh Hig Rada Toksikol 60: 19-26, 2009.

LUNDY PM, TREMBLAY KP: Ganglion blocking properties of some bispyridinium soman antagonists. Eur $J$ Pharmacol 60: 47-53, 1979.

LUO WQ, GE XL, CUI WY, WANG H: Targeting cholinesterase inhibitor poisoning with a novel blocker against both nicotinic and muscarinic receptors. Neurotox Res 18: 173-186, 2010.

MARRS TC: Organophosphate poisoning. Pharmacol Ther 58: 51-66, 1993.

MAYER ML, VYKLICKY L, CLEMENTS J: Regulation of NMDA receptor desensitization in mouse hippocampalneurons by glycine. Nature 338: 425-427, 1989.

PETROIANU GA, HASAN MY, NURULAIN SM, NAGELKERKE N, KASSA J, KUCA K: New K-oximes (K-27 and K-48) in comparison with obidoxime (LuH-6), HI-6, trimedoxime (TMB-4), and pralidoxime (2-PAM): survival in rats exposed IP to the organophosphate paraoxon. Toxicol Mech Methods 17: 401-408, 2007.

PUU G, ARTURSSON E, BUCHT G: Reactivation of nerve agent inhibited human acetylcholinesterases by HI- 6 and obidoxime. Biochem Pharmacol 35: 1505-1510, 1986.

RADIC Z, TAYLOR P: Structure and function of cholinesterases. In: Toxicology of Organophospate \& Carbamate Compounds. R GUPTA (ed), Elsevier Academic Press, London, 2006, pp 161-186.

ROMANELLI MN, GUALTIERI F: Cholinergic nicotinic receptors: competitive ligands, allosteric modulators, and their potential applications. Med Res Rev 23: 393-426, 2003.

SANTAFE MM, SALON I, GARCIA N, LANUZA MA, UCHITEL OD, TOMAS J: Muscarinic autoreceptors related with calcium channels in the strong and weak inputs at polyinnervated developing rat neuromuscular junctions. Neuroscience 123: 61-73, 2004.

SCHLAGMANN C, ULBRICH H, REMIEN J: Bispyridinium (oxime) compounds antagonize the ganglion blocking effect of pyridostigmine in isolated superior cervical-ganglia of the rat. Arch Toxicol 64: 482-489, 1990.

SCHOEPFER R, LUTHER M, LINDSTROM J: The human medulloblastoma cell line TE671 expresses a muscle-like acetylcholine receptor. Cloning of the alpha-subunit cDNA. FEBS Lett 226: 235-240, 1988.

SIVAGNANAM S: Potential therapeutic agents in the management of organophosphorus poisoning. Crit Care 6: 260261, 2002.

SOUKUP O, POHANKA M, TOBIN G, JUN D, FUSEK J, MUSILEK K, MAREK J, KASSA J, KUCA K: The effect of HI-6 on cholinesterases and on the cholinergic system of the rat bladder. Neuro Endocrinol Lett 29: 759$762,2008$.

SOUKUP O, TOBIN G, KUMAR UK, BINDER J, PROSKA J, JUN D, FUSEK J, KUCA K: Interaction of nerve agent antidotes with cholinergic systems. Curr Med Chem 17: 1708-1718, 2010a.

SOUKUP O, TOBIN G, KUMAR UK, JUN D, FUSEK J, KUCA K: Characterization of the anticholinergic properties of obidoxime; functional examinations of the rat atria and the urinary bladder. Toxicol Mech Methods 20: 428433, 2010b.

STRATTON MR, DARLING J, PILKINGTON GJ, LANTOS PL, REEVES BR, COOPER CS: Characterization of the human cell line TE671. Carcinogenesis 10: 899-905, 1989.

TATTERSALL JE: Ion channel blockade by oximes and recovery of diaphragm muscle from soman poisoning in vitro. Br J Pharmacol 108: 1006-1015, 1993. 
TOBIN G, EKSTROM J, BLOOM SR, EDWARDS AV: Atropine-resistant submandibular responses to stimulation of the parasympathetic innervation in the anaesthetized ferret. J Physiol 437: 327-339, 1991.

TRAN DQ, AMAKI Y, OHTA Y, NAGASHIMA H, DUNCALF D, FOLDES FF: Simultaneous in vivo measurement of nm block on three muscles. Anesthesiology 57: A276, 1982.

VAN DER KLOOT W, BALEZINA OP, MOLGO J, NAVES LA: The timing of channel opening during miniature endplate currents at the frog and mouse neuromuscular junctions: effects of fasciculin-2, other anti-cholinesterases and vesamicol. Pflugers Arch 428: 114-126, 1994.

VAN HELDEN HP, VAN DER WIEL HJ, DE LANGE J, BUSKER RW, MELCHERS BP, WOLTHUIS OL: Therapeutic eficacy of HI-6 in soman-poisoned marmoset monkeys. Toxicol Appl Pharmacol 115: 50-56, 1992.

VAN HELDEN HP, BUSKER RW, MELCHERS BP, BRUIJNZEEL PL: Pharmacological effects of oximes: how relevant are they? Arch Toxicol 70: 779-786, 1996.

VYKLICKY L JR, BENVENISTE M, MAYER ML: Modulation of N-methyl-D-aspartic acid receptor desensitization by glycine in mouse cultured hippocampal-neurons. J Physiol 428: 313-331, 1990. 